\title{
Two new species of Jalapriya and a new record, Dictyocheirospora vinaya from freshwater habitats in China
}

\author{
Xi Fu‡, Dan-Feng Bao§, Zong-Long Luo ${ }^{\ddagger}$, Xiu Hel, Hong-Yan Su‡ \\ $\ddagger$ College of Agriculture and Biological Sciences, Dali University, Dali, China \\ § Center of Excellence in Fungal Research, Mae Fah Luang University, Chiang Rai, Thailand \\ | Faculty of Life Science and Technology, Kunming University of Science and Technology, Kunming, China
}

Corresponding author: Hong-Yan Su (suhongyan16@163.com)

Academic editor: Ning Jiang

Received: 11 Sep 2021 | Accepted: 18 Oct 2021 | Published: 28 Oct 2021

Citation: Fu X, Bao D-F, Luo Z-L, He X, Su H-Y (2021) Two new species of Jalapriya and a new record, Dictyocheirospora vinaya from freshwater habitats in China. Biodiversity Data Journal 9: e74295.

https://doi.org/10.3897/BDJ.9.e74295

\begin{abstract}
Background

Pleosporales is the largest order of Dothideomycetes. In recent years, systematics of Pleosporales have undergone considerable revisions. Dictyosporiaceae is one of the newly established families within this order proposed to accommodate holomorphic saprobic Dothideomycetes. Currently 18 genera are recognised in Dictyosporiaceae.
\end{abstract}

\section{New information}

The new species, Jalapriya aquaticum sp. nov. and J. apicalivaginatum sp. nov. were collected from freshwater habitats in Gansu and Yunnan Provinces, China, respectively and are introduced, based on morphology and molecular analysis of combined ITS, LSU, SSU and TEF1- $\alpha$ sequence data. We also recovered one fresh collection of Dictyocheirospora vinaya D'souza, Bhat \& K.D. Hyde, which is a new record for China. Jalapriya aquaticum differs from extant species of Jalapriya in rows converging at the apex 
and apical cells with spherical-like appendages. Jalapriya apicalivaginatum differs from extant species of Jalapriya in having the rows of conidia mostly arranged in a plane. The phylogenetic analysis place the new collections within Dictyosporiaceae (Pleosporales). Descriptions and illustrations of Jalapriya aquaticum, J. apicalivaginatum and Dictyocheirospora vinaya are provided. A synopsis of characters of species of Jalapriya is also provided.

\section{Keywords}

asexual morphs, Dictyosporiaceae, freshwater fungi, phylogeny, taxonomy

\section{Introduction}

Pleosporales is the largest order of Dothideomycetes. In recent years, various families and genera in the Pleosporales have undergone considerable revisions (Goh and Hyde 1999, Cai et al. 2008, Tanaka et al. 2009, Zhang et al. 2009, Zhang et al. 2012, Hyde et al. 2013, Ariyawansa et al. 2015, Wang et al. 2016). Boonmee et al. (2016) accepted eleven genera in the family Dictyosporiaceae (Pleosporales) to accommodate most cheirosporous hyphomycetous genera that are saprobes on decaying wood and plant debris in terrestrial and freshwater habitats. One of the diagnostic characteristics of Dictyosporiaceae is their multicellular cheiroid conidia and this morphological feature distinguishes it from other families in the suborder Massarineae (Hyde et al. 2016). Liu et al. (2017) and Yang et al. (2018) updated the phylogenetic tree for Dictyosporiaceae and introduced two new genera Aquadictyospora and Dendryphiella in the family. Subsequently, three additional genera, Neodendryphiella, Pseudoconiothyrium and Paradictyocheirospora were added (IturrietaGonzález et al. 2018, Crous et al. 2019, Rajeshkumar et al. 2021). Currently, 18 genera are accepted in Dictyosporiaceae (Boonmee et al. 2016, Li et al. 2017, Iturrieta-González et al. 2018, Yang et al. 2018, Crous et al. 2019, Hyde et al. 2020, Dong et al. 2020, Rajeshkumar et al. 2021).

The genus Jalapriya was introduced by Boonmee et al. (2016) with Jalapriya pulchra D'souza, Su, Luo \& K.D. Hyde as type species; It is characterised by dark brown to black colonies, acrogenous, solitary and cheiroid conidia (Boonmee et al. 2016). Presently, three species are accepted in the genus, Jalapriya inflata, J. pulchra and J. toruloides.

Dictyocheirospora was established by Boonmee et al. (2016) to accommodate three new species, Dictyocheirospora bannica, $D$. rotunda and $D$. vinaya and four new combinations, $D$. gigantica, $D$. heptaspora, $D$. pseudomusae and $D$. subramanianii. Dictyocheirospora is characterised by non-complanate conidia with arms arising from the basal cell and closely gathered at the apex and compact (Wang et al. 2016). The species of Dictyocheirospora have been reported from freshwater and terrestrial habitats in China, Japan and Thailand (Jayasiri et al. 2015, Boonmee et al. 2016, Wang et al. 2016, Hyde et al. 2017, Li et al. 2017, Yang et al. 2018, Tibpromma et al. 2018, Phookamsak et al. 2019, Phukhamsakda 
et al. 2020). Currently, 23 species are accepted in the genus (Boonmee et al. 2016, Yang et al. 2018, Index Fungorum - Search Page).

In this study, two new species Jalapriya aquaticum and J. apicalivaginatum and a new geographic record, Dictyocheirospora vinaya are introduced, based on morphology and phylogenetic analyses. Detailed descriptions and illustrations are provided.

\section{Materials and methods}

\section{Isolation and morphological examination}

Submerged woody substrates were collected from dynamic waters, Gansu and Yunnan Provinces and taken back to the laboratory in Zip-lock plastic bags. The samples were incubated in plastic boxes lined with moistened tissue paper at room temperature for one week. Methods of morphological observation and isolation follow Luo et al. (2018) and Senanayake et al. (2020).

The pure cultures were developed by single spore isolation following the method provided by Chomnunti et al. (2014). The cultures are deposited in Kunming Institute of Botany, Chinese Academy of Sciences (KUMCC) and China General Microbiological Culture Collection Center (CGMCC). Herbarium specimens are deposited at the Herbarium of Cryptogams Kunming Institute of Botany Academia Sinica (Herb. HKAS). Facesoffungi and Index Fungorum numbers were obtained as in Jayasiri et al. (2015) and Index Fungorum Search Page.

\section{DNA extraction, PCR amplification and sequencing}

Genomic DNA was extracted from fresh mycelia grown on PDA at room temperature. The EZ geneTM Fungal gDNA kit (GD2416) was used to extract DNA according to the manufacturer's instructions. ITS, LSU, TEF1- $\alpha$, SSU gene regions were amplified using the primer pairs ITS5/ITS4, LROR/LR5, EF1-983F/EF1-2218R and NS1/NS4. The final volume of the PCR reaction was $25 \mu \mathrm{l}$ and contained $12.5 \mu \mathrm{l}$ of $2 \times$ Power Taq PCR MasterMix (a premix and ready-to-use solution, including 0.1 Units/ $\mu$ l Taq DNA Polymerase, $500 \mu \mathrm{M}$ dNTP Mixture each (dATP, dCTP, dGTP, dTTP), $20 \mathrm{mM}$ Tris- $\mathrm{HCl} \mathrm{pH} \mathrm{8.3,} 100 \mathrm{mM} \mathrm{KCl}, 3$ $\mathrm{mM} \mathrm{MgCl} 2$, stabiliser and enhancer), $1 \mu \mathrm{l}$ of each primer $(10 \mu \mathrm{M}), 1 \mu \mathrm{l}$ genomic DNA extract and $9.5 \mu \mathrm{l}$ deionised water. The PCR thermal cycle programme for ITS, LSU, TEF1a and SSU amplification was as follows: initial denaturation of $94^{\circ} \mathrm{C}$ for 3 minutes, followed by 35 cycles of denaturation at $94^{\circ} \mathrm{C}$ for 45 seconds, annealing at $56^{\circ} \mathrm{C}$ for 50 seconds, elongation at $72^{\circ} \mathrm{C}$ for 1 minute and the final extension at $72^{\circ} \mathrm{C}$ for 10 minutes. PCR products were purified using minicolumns, purification resin and buffer according to the manufacturer's protocols (Amershamproduct code: 27-9602-01). The sequencing works were carried by Tsingke Biological Engineering Technology and Services Co. Ltd (Yunnan, P.R. China). 


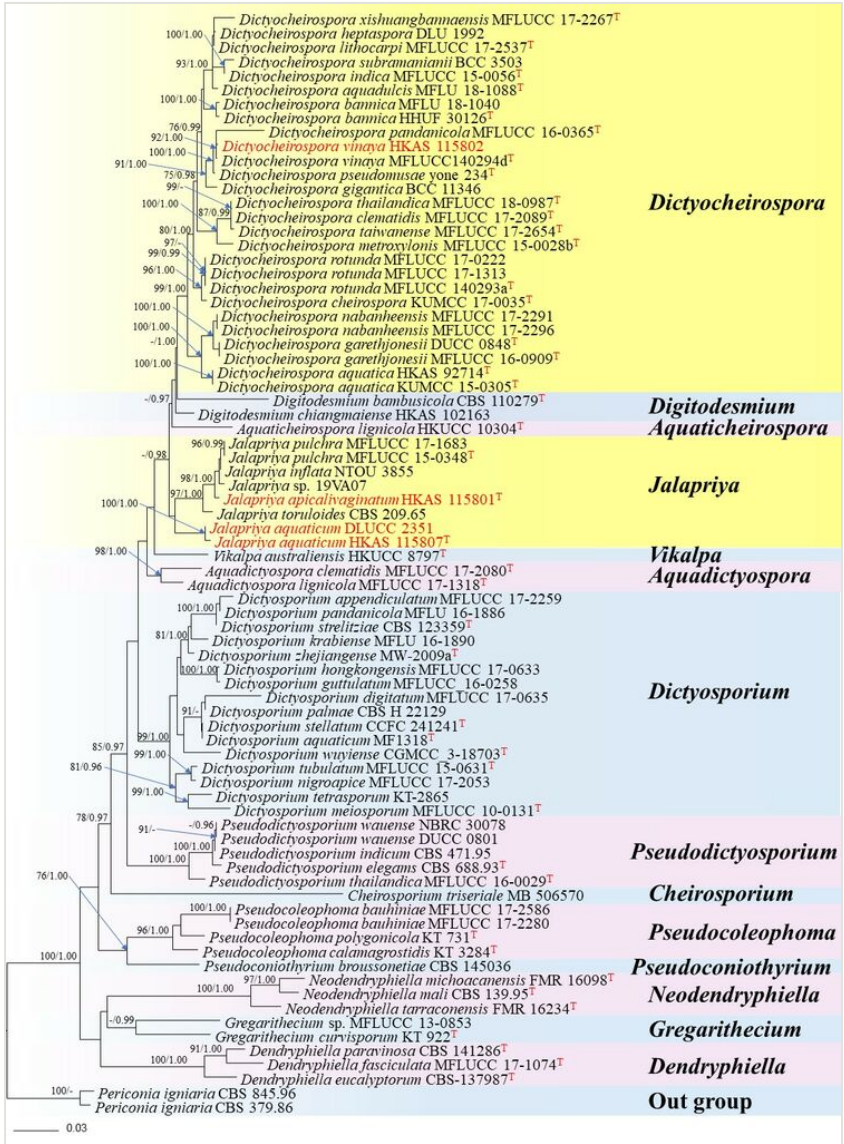

Figure 1. doi

RAxML tree generated from combined LSU, ITS, TEF1- $\alpha$ and SSU sequence data. Bootstrap support values for Maximum Likelihood (the first value) $\geq 75 \%$ and Bayesian posterior probabilities (the second value) $\geq 0.95$ are placed near the branches as ML/BYPP. The tree is rooted to Periconia igniaria (CBS 379.86 and CBS 845.96). Newly-generated sequences are indicated in red and strains isolated from the holotype and reference specimens are indicated with a red superscript $\mathrm{T}$.

\section{Phylogenetic analysis}

Sequence data for relevant strains were downloaded from GenBank following recent publications (Boonmee et al. 2016, Li et al. 2017, Wang et al. 2016). The consensus sequences were initially aligned using MAFFT v.7 (http://mafft.cbrc.jp/alignment/server/) (Katoh and Standley 2013) and optimised manually when needed. The aligned dataset was analysed by Maximum Likelihood (ML) and Bayesian Inference (BI).

Maximum Likelihood analysis was performed using RAxMLGUI v.1.3 (Silvestro and Michalak 2011). The optimal ML tree search was conducted with 1,000 separate runs using 
the default algorithm of the programme from a random starting tree for each run. The final tree was selected amongst suboptimal trees from each run by comparing the likelihood scores using the GTR+GAMMA substitution model. Maximum Likelihood bootstrap values equal to or greater than $75 \%$ were given as the first set of numbers above the nodes in the resulting ML tree (Fig. 1).

Bayesian analysis was conducted with MrBayes v.3.1.2 (Ronquist and Huelsenbeck 2003) to evaluate posterior probabilities (Rannala and Yang 1996) by Markov Chain Monte Carlo sampling (MCMC). The best-fit models of evolution were estimated by MrModeltest V.2.2 (Nylander and Uppsala University 2004). ITS, LSU and TEF selected the GTR+I+G model with inverse gamma-distributed rate in Bayesian analyses. SSU selected the GTR+G model with inverse gamma-distributed rate in Bayesian analyses. The $M L$ analyses were conducted with RAxML v.7.2.6 (Stamatakis and Alachiotis 2010) using a GTRGAMMA substitution model with 1000 bootstrap replicates. The robustness of the analyses was evaluated by bootstrap support (MLBS). Six simultaneous Markov chains were run for 10 million generations and trees were sampled every $100^{\text {th }}$ generation and 100,000 trees were obtained. The first 20,000 trees, representing the burn-in phase of the analyses, were discarded, while the remaining 80,000 trees were used to calculate posterior probabilities in the majority rule consensus tree (the critical value for the topological convergence diagnostic was 0.01). Through the posterior probabilities (PP) to reflect visually the reliability of each branch without the test for bootstrap method.

The phylogenetic trees were viewed and optimised in FigTree v.1.2.2 (Rambaut and Drummond 2008) and edited further using Microsoft Office PowerPoint. Newly-generated sequences in this study were deposited in GenBank (Table 1).

Table 1.

Isolates and sequences used in this study (newly-generated sequences are indicated in bold, strains isolated from the holotype and reference specimens are indicated in with a $\mathrm{T}$, without GenBank accession numbers are indicated in "_") .

\begin{tabular}{|c|c|c|c|c|c|c|}
\hline \multirow[t]{2}{*}{ Taxon } & \multicolumn{2}{|l|}{ Voucher/culture } & \multicolumn{4}{|c|}{ GenBank accession numbers } \\
\hline & & & ITS & LSU & TEF1 $\alpha$ & SSU \\
\hline \multicolumn{2}{|c|}{ Aquaticheirospora lignicola } & HKUCC $10304^{\top}$ & AY864770 & AY736378 & - & AY736377 \\
\hline \multicolumn{2}{|c|}{ Aquadictyospora clematidis } & MFLUCC $17-2080^{\top}$ & NR171871 & - & MT394727 & NG070646 \\
\hline \multicolumn{2}{|c|}{ A. lignicola } & MFLUCC $17-1318^{\top}$ & MF948621 & MF948629 & MF953164 & - \\
\hline \multicolumn{2}{|c|}{ Cheirosporium triseriale } & MB 506570 & EU413953 & EU413954 & - & - \\
\hline \multicolumn{2}{|c|}{ Dendryphiella eucalyptorum } & CBS $137987^{\top}$ & $\underline{\mathrm{KJ} 869139}$ & $\underline{\text { KJ869196 }}$ & - & - \\
\hline \multicolumn{2}{|c|}{ Den. fasciculata } & MFLUCC $17-1074^{\top}$ & MF399213 & $\underline{\text { MF399214 }}$ & - & - \\
\hline \multicolumn{2}{|c|}{ Den. paravinosa } & CBS $141286^{\top}$ & $\underline{\mathrm{KX} 228257}$ & $\underline{K X 228309}$ & - & - \\
\hline \multicolumn{2}{|c|}{ Dictyocheirospora aquadulcis } & MFLU $18-1088^{\top}$ & MK634545 & MK634542 & - & - \\
\hline \multicolumn{2}{|c|}{ Di. aquatica } & KUMCC $15-0305^{\top}$ & KY320508 & $\underline{\text { KY320513 }}$ & - & - \\
\hline \multicolumn{2}{|c|}{ Di. aquatica } & HKAS $92714^{\top}$ & $\underline{\text { NR154030 }}$ & - & - & - \\
\hline
\end{tabular}




\begin{tabular}{|c|c|c|c|c|c|c|}
\hline \multirow[t]{2}{*}{ Taxon } & \multirow{2}{*}{\multicolumn{2}{|c|}{ Voucher/culture }} & \multicolumn{4}{|c|}{ GenBank accession numbers } \\
\hline & & & \multirow{2}{*}{$\begin{array}{l}\text { ITS } \\
\text { NR154039 } \\
\end{array}$} & \multirow{2}{*}{$\begin{array}{l}\text { LSU } \\
\text { NG059061 } \\
\end{array}$} & \multirow{2}{*}{$\begin{array}{l}\text { TEF1 } \alpha \\
\text { AB808489 } \\
\end{array}$} & \multirow{2}{*}{$\begin{array}{l}\text { SSU } \\
\text { NG064841 } \\
\end{array}$} \\
\hline \multicolumn{2}{|c|}{ Di. bannica } & HHUF $30126^{\top}$ & & & & \\
\hline \multicolumn{2}{|c|}{ Di. bannica } & MFLU 18-1040 & $\underline{\mathrm{MH} 381765}$ & $\underline{\mathrm{MH} 381774}$ & - & $\underline{\mathrm{MH} 381759}$ \\
\hline \multicolumn{2}{|c|}{ Di. cheirospora } & KUMCC $17-0035^{\top}$ & $\underline{\text { MF177035 }}$ & $\underline{\text { MF177036 }}$ & - & MF928073 \\
\hline \multicolumn{2}{|c|}{ Di. clematidis } & MFLUCC $17-2089^{\top}$ & MT310593 & $\underline{\text { MT214546 }}$ & $\underline{\text { MT394728 }}$ & $\underline{\text { MT226665 }}$ \\
\hline \multicolumn{2}{|c|}{ Di. garethjonesii } & MFLUCC 16-0909 & $\underline{\mathrm{KY} 320509}$ & $\underline{\text { KY320514 }}$ & - & - \\
\hline \multicolumn{2}{|c|}{ Di. garethjonesii } & DUCC $0848^{\top}$ & MF948623 & $\underline{\text { MF948631 }}$ & $\underline{\text { MF953166 }}$ & - \\
\hline \multicolumn{2}{|c|}{ Di. gigantica } & BCC 11346 & $\underline{\mathrm{DQ} 018095}$ & - & - & - \\
\hline \multicolumn{2}{|c|}{ Di. heptaspora } & DLU 1992 & MT756244 & $\underline{\mathrm{MT} 756243}$ & - & - \\
\hline \multicolumn{2}{|c|}{ Di. indica } & MFLUCC $15-0056^{\top}$ & $\underline{\mathrm{MH} 381763}$ & $\underline{\mathrm{MH} 381772}$ & $\underline{\mathrm{MH} 388817}$ & $\underline{\mathrm{MH} 381757}$ \\
\hline \multicolumn{2}{|c|}{ Di. lithocarpi } & MFLUCC $17-2537^{\top}$ & $\underline{\text { NR163345 }}$ & $\underline{\text { NG070074 }}$ & - & $\underline{\text { NG065783 }}$ \\
\hline \multicolumn{2}{|c|}{ Di. metroxylonis } & MFLUCC $15-0028 b^{\top}$ & $\underline{\mathrm{MH} 742322}$ & $\underline{\mathrm{MH} 742314}$ & $\underline{\mathrm{MH} 764303}$ & $\underline{\mathrm{MH} 742318}$ \\
\hline \multicolumn{2}{|c|}{ Di. nabanheensis } & MFLUCC 17-2291 & $\underline{\text { MK347748 }}$ & $\underline{\text { MK347965 }}$ & $\underline{\text { MK360050 }}$ & - \\
\hline \multicolumn{2}{|c|}{ Di. nabanheensis } & MFLUCC 17-2296 & MK347756 & $\underline{\text { MK347973 }}$ & MK360051 & - \\
\hline \multicolumn{2}{|c|}{ Di. pandanicola } & MFLUCC $16-0365^{\top}$ & $\underline{\mathrm{MH} 388341}$ & $\underline{\mathrm{MH} 376713}$ & $\underline{\mathrm{MH} 388376}$ & - \\
\hline \multicolumn{2}{|c|}{ Di. pseudomusae } & Yone $234^{\top}$ & $\underline{\mathrm{LC} 014550}$ & $\underline{A B 807520}$ & $\underline{\mathrm{AB} 808496}$ & $\underline{\mathrm{AB} 797230}$ \\
\hline \multicolumn{2}{|c|}{ Di. rotunda } & MFLUCC 17-0222 & $\underline{\mathrm{MH} 381764}$ & $\underline{\mathrm{MH} 381773}$ & $\underline{\mathrm{MH} 388818}$ & $\underline{\mathrm{MH} 381758}$ \\
\hline \multicolumn{2}{|c|}{ Di. rotunda } & MFLUCC $140293 a^{\top}$ & $\underline{\text { KU179099 }}$ & $\underline{\text { KU179100 }}$ & - & - \\
\hline \multicolumn{2}{|c|}{ Di. rotunda } & MFLUCC 17-1313 & $\underline{\text { MF948625 }}$ & $\underline{\text { MF948633 }}$ & $\underline{\text { MF953168 }}$ & - \\
\hline \multicolumn{2}{|c|}{ Di. subramanianii } & BCC 3503 & $\underline{\mathrm{DQ} 018094}$ & $\underline{\mathrm{AB} 807520}$ & - & - \\
\hline \multicolumn{2}{|c|}{ Di. taiwanense } & MFLUCC 17-2654 ${ }^{\top}$ & $\underline{\text { MK495821 }}$ & $\underline{\text { MK495820 }}$ & - & - \\
\hline Di. thail & lica & MFLUCC $18-0987^{\top}$ & $\underline{\text { NR171885 }}$ & $\underline{\text { MN913743 }}$ & - & - \\
\hline Di. vina & & MFLUCC140294d ${ }^{\top}$ & KU179102 & $\underline{\text { KU179103 }}$ & - & $\underline{\text { KU179104 }}$ \\
\hline Di. vina & & HKAS 115802 & MZ618659 & $\underline{\text { MZ618660 }}$ & $\underline{\text { MZ851994 }}$ & - \\
\hline Di. xish & gbannaensis & MFLUCC 17-2267 & $\underline{\mathrm{MH} 388342}$ & $\underline{\mathrm{MH} 376714}$ & $\underline{\mathrm{MH} 388377}$ & - \\
\hline Dictyos, & ium appendiculatum & MFLUCC 17-2259 & $\underline{\mathrm{MH} 388343}$ & $\underline{\mathrm{MH} 376715}$ & - & - \\
\hline Dictyos. & uaticum & MF1318 ${ }^{\top}$ & KM610236 & - & - & - \\
\hline Dictyos. & gitatum & MFLUCC 17-0635 & $\underline{\mathrm{MH} 388344}$ & $\underline{\mathrm{MH} 376716}$ & $\underline{\mathrm{MH} 388378}$ & - \\
\hline Dictyos. & Ittulatum & MFLUCC 16-0258 & $\underline{\mathrm{MH} 388345}$ & $\underline{\mathrm{MH} 376717}$ & $\underline{\mathrm{MH} 388379}$ & $\underline{\mathrm{MH} 388312}$ \\
\hline Dictyos. & ngkongensis & MFLUCC 17-0633 & $\underline{\mathrm{MH} 388346}$ & $\underline{\mathrm{MH} 376718}$ & $\underline{\mathrm{MH} 388380}$ & NG068388 \\
\hline Dictyos. & eiosporum & MFLUCC $10-0131^{\top}$ & KP710944 & $\underline{\text { KP710945 }}$ & - & - \\
\hline Dictyos. & groapice & MFLUCC 17-2053 & $\underline{\mathrm{MH} 381768}$ & $\underline{\mathrm{MH} 381777}$ & $\underline{\mathrm{MH} 388821}$ & - \\
\hline Dictyos. & abiense & MFLU $16-1890$ & - & $\underline{\mathrm{MH} 376719}$ & $\underline{\mathrm{MH} 388381}$ & - \\
\hline Dictyos. & Imae & CBS H-22129 & - & $\underline{\mathrm{KX} 555648}$ & - & - \\
\hline Dictyos. & indanicola & MFLU 16-1886 & $\underline{\mathrm{MH} 388347}$ & $\underline{\mathrm{MH} 376720}$ & MH388382 & - \\
\hline Dictyos. & ellatum & CCFC $241241^{\top}$ & NR154608 & JF951177 & - & - \\
\hline
\end{tabular}




\begin{tabular}{|c|c|c|c|c|c|c|}
\hline \multirow[t]{2}{*}{ Taxon } & \multirow{2}{*}{\multicolumn{2}{|c|}{ Voucher/culture }} & \multicolumn{4}{|c|}{ GenBank accession numbers } \\
\hline & & & \multirow{2}{*}{$\begin{array}{l}\text { ITS } \\
\text { NR156216 } \\
\end{array}$} & \multirow{2}{*}{$\begin{array}{l}\text { LSU } \\
\text { FJ839653 } \\
\end{array}$} & \multirow{2}{*}{$\begin{array}{l}\text { TEF1a } \\
-\end{array}$} & \multirow{2}{*}{$\begin{array}{l}\text { SSU } \\
-\end{array}$} \\
\hline Dictyos & relitziae & CBS $123359^{\top}$ & & & & \\
\hline \multicolumn{2}{|c|}{ Dictyos. tetrasporum } & KT 2865 & $\underline{L}$ L014551 & AB807519 & AB808495 & _- \\
\hline \multicolumn{2}{|c|}{ Dictyos. tubulatum } & MFLUCC $15-0631^{\top}$ & $\underline{\mathrm{MH} 381769}$ & $\underline{\mathrm{MH} 381778}$ & $\underline{\mathrm{MH} 388822}$ & - \\
\hline \multicolumn{2}{|c|}{ Dictyos. wuyiense } & CGMCC $3-18703^{\top}$ & $\underline{\text { KY072977 }}$ & - & - & - \\
\hline \multicolumn{2}{|c|}{ Dictyos. zhejiangense } & $M W-2009 a^{\top}$ & $\underline{\text { FJ456893 }}$ & - & - & - \\
\hline \multicolumn{2}{|c|}{ Dictyos. bambusicola } & CBS $110279^{\top}$ & $\underline{\mathrm{DQ} 018091}$ & $\underline{D Q 018103}$ & - & - \\
\hline \multicolumn{2}{|c|}{ Dictyos. chiangmaiense } & HKAS 102163 & _ & MK571766 & _ & MK571775 \\
\hline \multicolumn{2}{|c|}{ Gregarithecium curvisporum } & KT $922^{\top}$ & $\underline{\mathrm{AB} 809644}$ & $\underline{\mathrm{AB} 807547}$ & - & $\underline{\text { AB797257 }}$ \\
\hline \multicolumn{2}{|c|}{ Gregarithecium sp. } & MFLUCC 13-0853 & KX364281 & KX364282 & _ & KX364283 \\
\hline \multicolumn{2}{|c|}{ Jalapriya apicalivaginatum } & HKAS $115801^{\top}$ & $\underline{\text { MZ621167 }}$ & $\underline{M Z 621168}$ & - & - \\
\hline \multicolumn{2}{|c|}{ J. aquaticum (2101) } & HKAS $115807^{\top}$ & MZ621152 & $\underline{\text { MZ621169 }}$ & $\underline{\text { MZ851995 }}$ & MZ621170 \\
\hline \multicolumn{2}{|c|}{ J. aquaticum (2351) } & DLUCC 2351 & $\underline{M Z 621151}$ & MZ621165 & - & MZ621166 \\
\hline \multicolumn{2}{|c|}{ J. inflata } & NTOU 3855 & JQ267362 & JQ267363 & - & JQ267361 \\
\hline \multicolumn{2}{|c|}{ J. pulchra } & MFLUCC $15-0348^{\top}$ & $\underline{\text { KU179108 }}$ & $\underline{\text { KU179109 }}$ & - & $\underline{\text { KU179110 }}$ \\
\hline \multicolumn{2}{|c|}{ J. pulchra } & MFLUCC 17-1683 & MF948628 & $\underline{\text { MF948636 }}$ & $\underline{\text { MF953171 }}$ & - \\
\hline \multicolumn{2}{|c|}{ Jalapriya sp. } & 19VA07 & $\underline{\mathrm{JX} 270548}$ & - & - & - \\
\hline \multicolumn{2}{|c|}{ J. toruloides } & CBS 209.65 & $\underline{\mathrm{DQ} 018093}$ & $\underline{\mathrm{DQ} 018104}$ & - & DQ018081 \\
\hline \multicolumn{2}{|c|}{ Neodendryphiella mali } & CBS $139.95^{\top}$ & $\underline{\text { LT906655 }}$ & $\underline{\text { LT906657 }}$ & - & - \\
\hline \multicolumn{2}{|c|}{ N. michoacanensis } & FMR $16098^{\top}$ & $\underline{\text { LT906660 }}$ & $\underline{\text { LT906658 }}$ & - & - \\
\hline \multicolumn{2}{|c|}{ N. tarraconensis } & FMR $16234^{\top}$ & $\underline{\text { LT906659 }}$ & $\underline{\text { LT906656 }}$ & - & - \\
\hline \multicolumn{2}{|c|}{ Periconia igniaria } & CBS 379.86 & $\underline{\mathrm{LC} 014585}$ & $\underline{\mathrm{AB} 807566}$ & $\underline{A B 808542}$ & AB797276 \\
\hline \multicolumn{2}{|c|}{$P$. igniaria } & CBS 845.96 & $\underline{\mathrm{LC} 014586}$ & $\underline{A B 807567}$ & $\underline{\mathrm{AB} 808543}$ & GU296171 \\
\hline Pseudo & eophoma bauhiniae & MFLUCC 17-2280 & MK347735 & MK347952 & $\underline{\text { MK360075 }}$ & MK347843 \\
\hline Pseudo & bauhiniae & MFLUCC 17-2586 & MK347736 & MK347953 & MK360076 & MK347844 \\
\hline Pseudo & alamagrostidis & KT $3284^{\top}$ & $\underline{\mathrm{LC} 014592}$ & $\underline{\text { LC014609 }}$ & $\underline{\mathrm{LC} 014614}$ & $\underline{\text { LC014604 }}$ \\
\hline Pseudo & oolygonicola & $\mathrm{KT} 731^{\top}$ & AB809634 & $\underline{\mathrm{AB} 807546}$ & $\underline{A B 808522}$ & $\underline{A B 797256}$ \\
\hline Pseudo & yphicola & MFLUCC $16-0123^{\top}$ & KX576655 & KX576656 & - & - \\
\hline Pseudo & hiothyrium broussonetiae & CBS 145036 & MK442618 & MK442554 & MK442709 & _ \\
\hline Pseudo & tyosporium elegams & CBS $688.93^{\top}$ & MH862454 & MH874101 & - & DQ018084 \\
\hline Pseudo & indicum & CBS 471.95 & $\underline{\mathrm{DQ} 018097}$ & - & - & - \\
\hline Pseudo & thailandica & MFLUCC $16-0029^{\top}$ & $\underline{\mathrm{KX} 259520}$ & $\underline{K X 259522}$ & $\underline{K X 259526}$ & $\underline{K X 259524}$ \\
\hline Pseudo & wauense & NBRC 30078 & $\underline{\mathrm{DQ} 018098}$ & $\underline{\mathrm{DQ} 018105}$ & - & $\underline{\mathrm{DQ} 018083}$ \\
\hline Pseudo & wauense & DUCC 0801 & MF948622 & $\underline{\text { MF948630 }}$ & $\underline{\text { MF953165 }}$ & - \\
\hline Vikalpa & traliensis & HKUCC $8797^{\top}$ & DQ018092 & - & - & - \\
\hline
\end{tabular}




\section{Taxon treatments}

Jalapriya apicalivaginatum D.F. Bao, X. Fu, H.Y. Su \& Z.L. Luo, 2021, sp. nov.

- IndexFungorum $\underline{558682}$

- $\quad$ Species-ID Facesoffungi number: FoF 10257

\section{Material}

Holotype:

a. $\quad$ scientificName: Jalapriya apicalivaginatum; phylum: Ascomycota; class:

Dothideomycetes; order: Pleosporales; family: Dictyosporiaceae; genus: Jalapriya; locationRemarks: China, Gansu Province, Gannan City, Xiahe County, Sangke Town, on decaying wood submerged in stream, July 2020; habitat: decaying wood submerged in stream; collectionID: SK 1-21-1 H; collectionCode: L-78

\section{Description}

Saprobic on decaying wood submerged in stream. Asexual morph: Hyphomycetous (Fig. 2). Colonies effuse, scattered, dark brown or black. Mycelium mostly immersed, partly superficial, composed of smooth, septate, branched, hyaline to pale brown hyphae. Conidiophores micronematous, reduced, hyaline to pale brown, unbranched, thin-walled, smooth. Conidiogenous cells holoblastic, integrated, terminal. Conidia acrogenous, solitary, cheiroid, pale brown, the shape of conidia like a "U", with 3-5 rows of cells. The rows in the middle are little bit longer than the outer rows and each row of cells with an apical hyaline, inflated, gelatinous subglobose, cap-like appendage, the rows of conidia mostly arranged in a plane and 2 outer rows arising from a basal cell, rows not separating, each row consisting of 6-12 cells, the size of outer rows 15$52 \times 3-6 \mu \mathrm{m}(\bar{x}=36 \times 5 \mu \mathrm{m}, \mathrm{n}=30)$, excluding apical hyaline gelatinous appendages, the size of inner rows $24-47 \times 4-7 \mu \mathrm{m}(\overline{\mathrm{x}}=40 \times 5.5 \mu \mathrm{m}, \mathrm{n}=30)$. The size of conidia 24-47 × 17-31.5 $\mu \mathrm{m}(\bar{x}=40 \times 23 \mu \mathrm{m}, \mathrm{n}=30)$. Sexual morph: Undetermined.

Culture characteristics: Conidia germinating on PDA within $24 \mathrm{~h}$, germ tubes arising from the outermost cells of the conidium. Colonies on MEA covering $9 \mathrm{~cm}$ diam., in 4 weeks at $28^{\circ} \mathrm{C}$. On the obverse, the edges are white and the middle is greyish-white. On the reverse, colonies appear pale yellow. Sporulation not observed in culture.

Material examined: CHINA, Gansu Province, Gannan City, Xiahe County, Sangke Town, $35^{\circ} 8^{\prime} 9 " \mathrm{~N}, 102^{\circ} 27^{\prime} 11 " \mathrm{E}$, on decaying wood submerged in stream, July 2020 , Z.L. Luo, SK 1-21-1 H (HKAS 115801, holotype), ex-type living culture, KUNCC 21-10704 $=$ CGMCC 3.20612 .

\section{Etymology}

Referring to the conidia with an apical mucilaginous sheath. 


\section{Notes}

In the phylogenetic analysis, J. apicalivaginatum formed a distinct lineage within Jalapriya and close to Jalapriya sp. (19VA07); However, the morphology of Jalapriya sp. (19VA07) was not available, but phylogeny of $J$. apicalivaginatum and Jalapriya sp. are distinct. Jalapriya apicalivaginatum resembles $\mathrm{J}$. pulchra and $\mathrm{J}$. inflata in having each conidial row of cells with an apical hyaline, inflated, gelatinous subglobose, caplike appendage. However, Jalapriya inflata is characterised by branched conidiophores, whereas conidiophores of $J$. apicalivaginatum are not differentiated. Jalapriya apicalivaginatum has fewer number of rows than those of $J$. pulchra (3-5 rows vs. 5-7 rows) and conidia are smaller than those of J. pulchra (24-47 × 17-31.5 $\mu \mathrm{m}$ vs. 32-46 $\times$ 23.5-31.5 $\mu \mathrm{m})($ Boonmee et al. 2016) (Table 2).

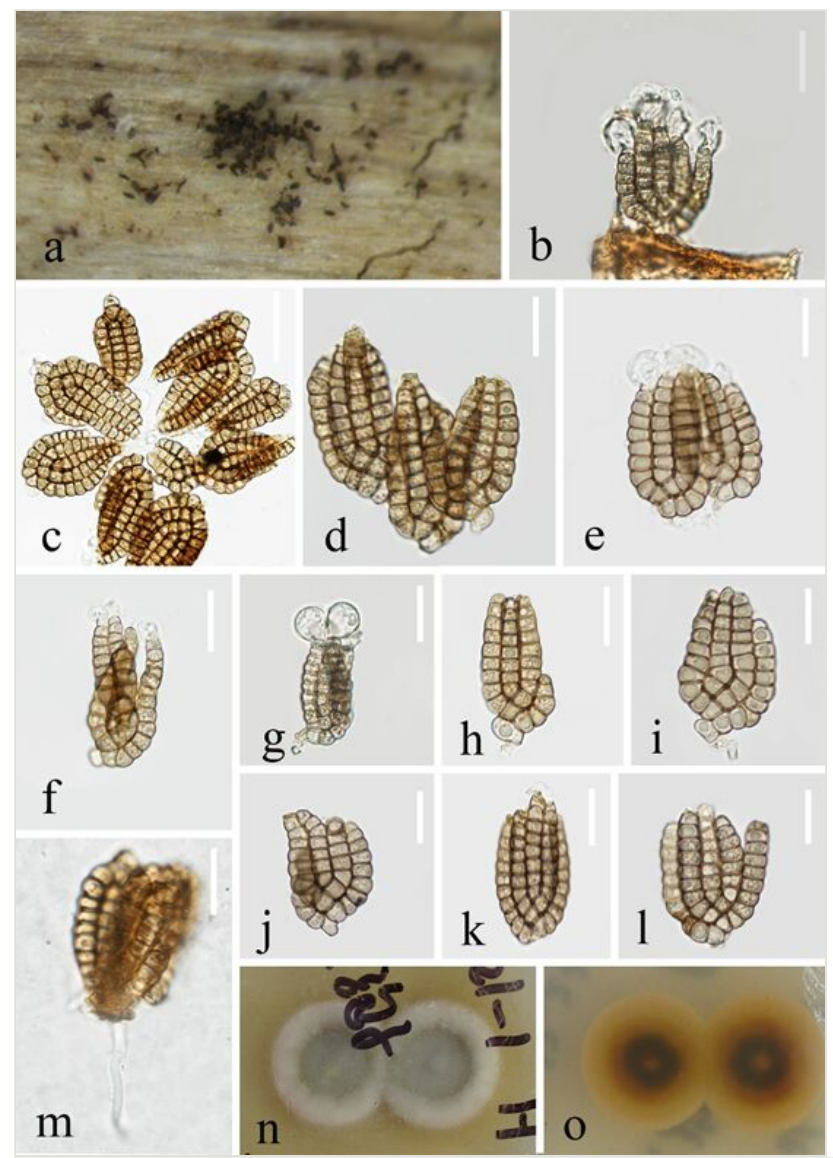

Figure 2. doi

Jalapriya apicalivaginatum (HKAS 115801, holotype). a Colonies on submerged wood; b-I Conidia; $\mathbf{m}$ Germinating conidium; $\mathbf{n}-\mathbf{o}$ Culture on PDA from above and reverse. Scale bars: $b$, f-g, $20 \mu \mathrm{m}$; c, $30 \mu \mathrm{m}$; d-e, h-m, $15 \mu \mathrm{m}$. 
Table 2.

A synopsis of characters of species of Jalapriya.

\begin{tabular}{|c|c|c|c|c|c|c|}
\hline \multirow[t]{2}{*}{ Species } & \multicolumn{4}{|l|}{ Conidia } & \multirow[t]{2}{*}{ Distribution } & \multirow[t]{2}{*}{ Reference } \\
\hline & Shape & $\begin{array}{l}\text { Size } \\
(\mu \mathrm{m})\end{array}$ & Colour & $\begin{array}{l}\text { Number } \\
\text { of rows }\end{array}$ & & \\
\hline Jalapriya inflata & $\begin{array}{l}\text { Euseptate, thin- } \\
\text { walled and } \\
\text { staurosporous, } \\
\text { composed of an } \\
\text { apically inflated } \\
\text { basal cell }\end{array}$ & $\begin{array}{l}28.5- \\
38 \times \\
14.5- \\
21.5\end{array}$ & Brown & $\begin{array}{l}3-4 \\
\text { rows }\end{array}$ & $\begin{array}{l}\text { UK, Ontario, } \\
\text { On rotten wood }\end{array}$ & $\begin{array}{l}\text { Matsushima 1983, } \\
\text { Kirschner et al. } \\
\text { 2013, Boonmee et } \\
\text { al. 2016, Iturrieta- } \\
\text { González et al. } \\
2018\end{array}$ \\
\hline J. pulchra & $\begin{array}{l}\text { Acrogenous, solitary, } \\
\text { each row of cells } \\
\text { with an apical } \\
\text { hyaline, inflated, } \\
\text { gelatinous } \\
\text { subglobose, cap-like } \\
\text { appendage }\end{array}$ & $\begin{array}{l}32-46 \\
\times \\
23.5- \\
31.5\end{array}$ & $\begin{array}{l}\text { Uniformly } \\
\text { pale to } \\
\text { medium } \\
\text { reddish- } \\
\text { brown }\end{array}$ & $\begin{array}{l}5-7 \\
\text { rows }\end{array}$ & $\begin{array}{l}\text { CHINA, } \\
\text { Yunnan } \\
\text { Province, on } \\
\text { decaying wood } \\
\text { submerged in } \\
\text { stream }\end{array}$ & $\begin{array}{l}\text { Boonmee et al. } \\
2016 \text {, Iturrieta- } \\
\text { González et al. } \\
2018\end{array}$ \\
\hline J. aquaticum & $\begin{array}{l}\text { Acrogenous, solitary, } \\
\text { rows converging at } \\
\text { apex, apical cells } \\
\text { with spherical-like } \\
\text { appendages }\end{array}$ & $\begin{array}{l}22-53 \\
\times 16- \\
24\end{array}$ & $\begin{array}{l}\text { Pale to } \\
\text { medium } \\
\text { brown }\end{array}$ & $\begin{array}{l}3-4 \\
\text { rows }\end{array}$ & $\begin{array}{l}\text { CHINA, } \\
\text { Yunnan } \\
\text { Province, on } \\
\text { decaying wood } \\
\text { submerged in } \\
\text { stream }\end{array}$ & This study \\
\hline $\begin{array}{l}J . \\
\text { apicalivaginatum }\end{array}$ & $\begin{array}{l}\text { Acrogenous, solitary, } \\
\text { thin-walled, each } \\
\text { row of cells with an } \\
\text { apical hyaline, } \\
\text { inflated, gelatinous } \\
\text { subglobose, cap-like } \\
\text { appendage }\end{array}$ & $\begin{array}{l}24-47 \\
\times 17- \\
31.5\end{array}$ & pale brown & $\begin{array}{l}3-5 \\
\text { rows }\end{array}$ & $\begin{array}{l}\text { CHINA, Gansu } \\
\text { Province, on } \\
\text { decaying wood } \\
\text { submerged in } \\
\text { stream }\end{array}$ & This study \\
\hline
\end{tabular}

\section{Jalapriya aquaticum D.F. Bao, X. Fu, H.Y. Su \& Z.L. Luo, 2021, sp. nov.}

- IndexFungorum 558683

- $\quad$ Species-ID Facesoffungi number: FoF 10258

\section{Material}

\section{Holotype:}

a. scientificName: Jalapriya aquaticum; phylum: Ascomycota; class: Dothideomycetes; order: Pleosporales; family: Dictyosporiaceae; genus: Jalapriya; locationRemarks: China, Yunnan Province, Dali, Cangshan Mountain, Lingquan stream, on decaying wood submerged in stream, April 2019; habitat: Saprobic on decaying wood submerged in stream; collectionID: 1LQX III H Z-7-1; collectionCode: S-2101 


\section{Description}

Saprobic on decaying wood submerged in stream. Asexual morph: Hyphomycetous (Fig. 3). Colonies punctiform, sporodochial, velvety, dark brown to black. Conidiophores micronematous, subhyaline to pale brown hyphae, unbranched, thin-walled, smooth. Mycelium immersed, composed of brown, smooth, thin-walled, septate. Conidiogenous cells holoblastic, integrated, terminal. Conidia acrogenous, solitary, cheiroid, pale to medium brown, with 3-4 rows of cells, rows converging at apex, apical cells with spherical-like appendages, the immature conidia are slightly curved and become straight after maturity. Two outer rows arising from a basal cell, rows not separating, each row consisting of $6-12$ cells, the size of outer rows $29-53 \times 6-8 \mu \mathrm{m}(\bar{x}=45 \times 5$ $\mu \mathrm{m}, \mathrm{n}=30$ ), excluding apical hyaline gelatinous appendages, the size of inner rows $22-44 \times 4-8 \mu \mathrm{m}(\bar{x}=38 \times 6 \mu \mathrm{m}, \mathrm{n}=30)$. The size of conidia $22-53 \times 16-24 \mu \mathrm{m}$. Sexual morph: Undetermined.

Culture characteristics: Conidia germinating on PDA within $24 \mathrm{~h}$, germ tubes arising from the outermost cells of the conidium. Colonies on MEA covering $9 \mathrm{~cm}$ diam., in 4 weeks, at $28^{\circ} \mathrm{C}$, white to cream. Sporulation not observed in culture.

Material examined: CHINA, Yunnan Province, Dali, Cangshan Mountain, Lingquan stream, $25.747501^{\circ} \mathrm{N}, 100.090989^{\circ} \mathrm{E}$, on decaying wood submerged in stream, April 2019, Z.Q. Zhang, 1LQX III H Z-7-1 (S-2101) (HKAS 115807, holotype), ex-type living culture, KUNCC 21-10705 = DLUCC 2101 = CGMCC 3.20613; ibid. July 2019, Zhengquan Zhang, 2LQX III Z-56-1 H (S-2351), living culture, KUNCC 21-10706 = DLUCC 2101.

\section{Etymology}

Referring to the species collected from aquatic habitats.

\section{Notes}

In the phylogenetic analysis, J. aquaticum nested in Jalapriya and sister to $J$. toruloides. Morphologically, J. aquaticum is similar to $\mathrm{J}$. inflata in having 3-4 rows of conidia, but differs from $\mathrm{J}$. inflat in the shape of the conidia, the cells of $\mathrm{J}$. inflata are fuller and more three-dimensional. J. inflata arranged more loosely in the rows of conidia and $J$. aquaticum packed more tightly. J. aquaticum has larger conidia than those of J. inflata $(22-53 \times 16-24$ vs. $28.5-38 \times 14.5-21.5 \mu \mathrm{m})$. Jalapriya quaticum similar to J. pulchra in having appendages on the apical cells of the conidia, but differs in the rows of $J$. aquaticum not being separable without manual force.

\section{Dictyocheirospora vinaya D'souza, Bhat \& K.D. Hyde, 2016, Fungal Diversity 80: 465}




\begin{abstract}
Material
Holotype:

a. $\quad$ scientificName: Dictyocheirospora vinaya; phylum: Ascomycota; class: Dothideomycetes; order: Pleosporales; family: Dictyosporiaceae; genus: Dictyocheirospora; locationRemarks: Thailand. Chiang Mai, Mushroom Research Centre, on submerged wood in a freshwater stream, 24 November 2013; habitat: submerged wood in a freshwater stream; identifiedBy: D'souza, Bhat \& K.D. Hyde; type: MFLU 14-0264; collectionCode: MJD-26; source: https://doi.org/10.1007/s13225-016-0363-z
\end{abstract}

\title{
Description
}

Saprobic on decaying wood in streams. Asexual morph: Hyphomycetous (Fig. 4). Colonies punctiform, sporodochial, velvety, dark brown. Mycelium immersed, composed of pale brown, smooth, thin-walled septate, branched, 1-2 $\mu \mathrm{m}$ wide hyphae. Conidiophores 9-27 $\times 3-6 \mu \mathrm{m}(\overline{\mathrm{x}}=15 \times 5 \mu \mathrm{m}, \mathrm{n}=18)$, micronematous to semimacronematous, pale brown, smooth, thin-walled. Conidiogenous cells holoblastic, integrated, terminal, determinate, pale brown. Conidia solitary, terminal, cheiroid, 48$110 \times 14-32 \mu \mathrm{m}(\overline{\mathrm{x}}=73 \times 22 \mu \mathrm{m}, \mathrm{n}=30)$, pale brown, consisting of 7 rows of cells; rows digitate, arising from a basal cell, each arm consisting of 10-20 cells, distoseptate, constricted at septa, rows appressed when young, inwardly curved the tip, palmately divergent when squashed, smooth-walled, guttulate. Sexual morph: Undetermined.

Culture characteristics: Conidia germinating on water agar within $24 \mathrm{~h}$, germ tubes emerging from the basal cells of the conidium. Colonies on PDA covering $9 \mathrm{~cm}$ diam., in 4 weeks, at $28^{\circ} \mathrm{C}$, with wavy margins, at first white, later becoming orange. Sporulating regions scattered, but mostly confined to the centre of the culture.

Material examined: CHINA, Yunnan Province, Nanpanjiang River, 24³3'57.48"N, $103^{\circ} 06^{\prime} 44.44 " \mathrm{E}$, on decaying wood submerged in stream, 23 February 2018, X. He, NPJ H 3-2-1 (HKAS 115802); living culture KUNCC 21-10707.

\section{Notes}

Dictyocheirospora vinaya, the type species of Dictyocheirospora, was introduced by Boonmee et al. (2016). Dictyocheirospora vinaya is characterised by punctiform, dark brown colonies, pale brown, solitary, terminal, cheiroid conidia. Our fresh collection fits perfectly with the original description of $D$. vinaya (Boonmee et al. 2016). Phylogenetic analyses showed that our strain (DLUCC 1674) clustered with the ex-type strain of $D$. vinaya with high bootstrap support (93\% ML and $1.00 \mathrm{PP})$. ITS comparison between our strain and MFLUCC 14-0294 revealed that there is no difference in a total of 499 bp, comparison of LSU between our strain and MFLUCC 14-0294 revealed 3 bp differences in a total of $1252 \mathrm{bp}$. Thus, we identified our new collection as $D$. vinaya, based on both phylogeny and morphology. Dictyocheirospora vinaya MFLUCC 140294 collected from freshwater habitats in Thailand, while our new collection was collected from freshwater habitats in China. It is a new record for China. 

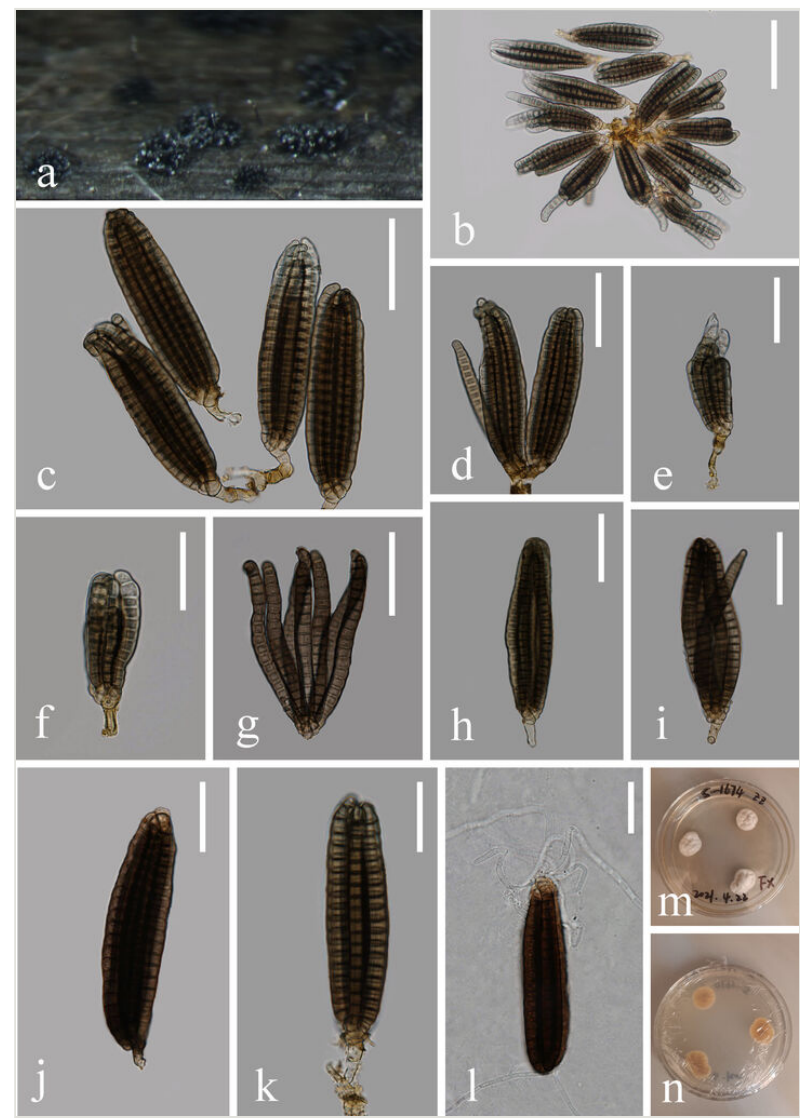

Figure 4. doi

Dictyocheirospora vinaya (HKAS 115802). a Colonies on submerged wood; b Squash mount of conidioma; c-k Conidia; I Germinating conidium; $\mathbf{m}-\mathbf{n}$ Culture on PDA from above and reverse. Scale bars: b, $50 \mu \mathrm{m}$; c-d, h-k, $40 \mu \mathrm{m}$; e-g, I, $30 \mu \mathrm{m}$.

\section{Identification keys}

\section{Key to Jalapriya species}

\begin{tabular}{|l|l|l|}
\hline 1 & Conidia without appendages & J. toruloides \\
\hline- & Conidia with appendages & 3 \\
\hline 2 & Conidia composed of 5-7 rows & J. pulchra \\
\hline- & Conidia composed of $3-5$ rows & 3 \\
\hline
\end{tabular}




\begin{tabular}{|l|l|l|}
\hline 3 & Conidia $28.5-38 \times 14.5-21.5 \mu \mathrm{m}$ & J. inflata \\
\hline- & The size of conidia not as above & 4 \\
\hline 4 & Apical cell of conidia with spherical-like appendages & J. aquaticum \\
\hline- & Apical cell of conidia with cap-like appendages & J. apicalivaginatum \\
\hline
\end{tabular}

\section{Analysis}

\section{Phylogenetic analysis}

The combined ITS, LSU, TEF1- $\alpha$ and SSU dataset consisted 78 sequences representing all genera of the Dictyosporiaceae with Periconia igniaria (CBS 379.86 and CBS 845.96) as outgroup taxon. The best scoring RaxML tree with the final ML optimisation likelihood value of -20943.450686 is shown here (Fig. 1). The alignment comprised 4309 characters including gaps. The matrix had 1309 distinct alignment patterns, with $51.74 \%$ undetermined characters or gaps. Estimated base frequencies were as follows: $A=$ $0.241918, C=0.244332, G=0.269566, T=0.244184$; substitution rates $A C=1.667496$, $A G=3.298982, A T=2.345910, C G=0.903092, C T=8.345950, G T=1.000000 ;$ Tree Length $=1.761576$.

Two newly-collected Jalapriya aquaticum isolates grouped with species of Jalapriya and basal to the genus with highly-supported value (100 ML/1.00 PP). Jalapriya apicalivaginatum formed a distinct lineage between J. toruloides and Jalapriya sp. (19VA07) with high bootstrap (97 ML/1.00 PP). Dictyocheirospora vinaya (HKAS 115802) clustered with its ex-type strains with high support (93 ML/1.00 PP).

\section{Discussion}

Dictyosporiaceae accommodates a holomorphic group of Dothideomycetes, including 18 genera (Hyde et al. 2019, Rajeshkumar et al. 2021). Dictyocheirospora is the second largest genus of Dictyosporiaceae, followed by Dictyosporium. Dictyocheirospora is morphologically similar to Dictyosporium in having cheiroid, cylindrical conidia; However, Dictyocheirospora differs from Dictyosporium in having non-complanate conidia with arms arising from the basal cell and closely gathered at the apex and compact, while Dictyosporium has complanate conidia without separating arms. Thus, eight species were transferred from Dictyosporium to Dictyocheirospora, based on themorphological characters and phylogenetic analyses. (Boonmee et al. 2016, Yang et al. 2018). Dictyocheirospora is cosmopolitan in distribution and commonly reported from freshwater habitats in China, India, Japan and Thailand. Nine species of Dictyocheirospora were found on submerged decaying wood, others were found in terrestrial habitats. Currently, nine species have been discovered in China including Dictyocheirospora vinaya, which is mentioned in this article. (Boonmee et al. 2016, Wang et al. 2016, Hyde et al. 2017, Li et 
al. 2017, Yang et al. 2018, Tibpromma et al. 2018, Jayasiri et al. 2015, Phookamsak et al. 2019, Phukhamsakda et al. 2020, Rajeshkumar et al. 2021).

Currently, three species are accepted in Jalapriya, of which, J. toruloides (Corda) is a terrestrial species discovered by Henningsson (1974) in Sweden; Afterwards it has been found in subtropical to temperate areas of both hemispheres, seemingly more often reported from coastal localities, considered an euryhaline species (Tibell et al. 2020), but our fresh collections are all from submerged wood in freshwater lotic habitats. In addition, both J. pulchra and J. acuaticum were all found in Yunnan Province, China on decaying wood submerged in a stream (Table 2). The morphological differences between $J$. apicalivaginatum and $\mathrm{J}$. pulchra are not significant, but they are phylogenetically distinct. Morphology of $\mathrm{J}$. toruloides is not available; However, the new species $\mathrm{J}$. aquaticum forms a distinct clade from $J$. toruloides. Jalapriya aquaticum is different from other species in Jalapriya and forms a separate branch with high support value (100\% ML and 1.00 BYPP).

\section{Acknowledgements}

This research was financed and supported by the National Natural Science Foundation of China (Project ID: 31860006, 31970021) and Fungal diversity conservation and utilisation innovation team of Dali University (ZKLX2019213). We thank Zheng-quan Zhang, Jian-wei Li, Lv He and Xiang Hong for the help on collecting samples. Xi Fu thanks Yi-Le Wan, You $\mathrm{Mu}$ and Yan Tao for their help on isolation and morphological examination, DNA extraction and PCR amplification. We are grateful to Hong-Wei Shen for his valuable suggestions and help.

\section{References}

- $\quad$ Ariyawansa H, Phukhamsakda C, Thambugala K, Bulgakov T, Wanasinghe D, Perera R, Mapook A, Camporesi E, Kang J, Gareth Jones EB, Bahkali A, Jayasiri S, Hyde K, Liu Z, Bhat JD (2015) Revision and phylogeny of Leptosphaeriaceae. Fungal Diversity 74 (1): 19-51. https://doi.org/10.1007/s13225-015-0349-2

- Boonmee S, D'souza M, Luo Z, Pinruan U, Tanaka K, Su H, Bhat D, McKenzie EC, Jones EBG, Taylor J, Phillips AL, Hirayama K, Eungwanichayapant P, Hyde K (2016) Dictyosporiaceae fam. nov. Fungal Diversity 80 (1): 457-482. https://doi.org/10.1007/ s13225-016-0363-Z

- Cai L, Guo XY, Hyde KD (2008) Morphological and molecular characterisation of a new anamorphic genus Cheirosporium, from freshwater in China. Persoonia - Molecular Phylogeny and Evolution of Fungi 20 (1): 53-58. https://doi.org/10.3767/00315 8508x314732

- $\quad$ Chomnunti P, Hongsanan S, Aguirre-Hudson B, Tian Q, Peršoh D, Dhami M, Alias A, Xu J, Liu X, Stadler M, Hyde K (2014) The sooty moulds. Fungal Diversity 66 (1): 1-36. https://doi.org/10.1007/s13225-014-0278-5

- $\quad$ Crous PW, Schumacher RK, Akulov A, Thangavel R, Hernández-Restrepo M, Carnegie AJ, Cheewangkoon R, Wingfield MJ, Summerell BA, Quaedvlieg W, Coutinho TA, Roux 
J, Wood AR, Giraldo A, Groenewald JZ (2019) New and Interesting Fungi. 2. Fungal Systematics and Evolution 3 (1): 57-134. https://doi.org/10.3114/fuse.2019.03.06

- $\quad$ Dong W, Wang B, Hyde K, McKenzie EC, Raja H, Tanaka K, Abdel-Wahab M, AbdelAziz F, Doilom M, Phookamsak R, Hongsanan S, Wanasinghe D, Yu X, Wang G, Yang $\mathrm{H}$, Yang J, Thambugala K, Tian Q, Luo Z, Yang J, Miller A, Fournier J, Boonmee S, Hu D, Nalumpang S, Zhang H (2020) Freshwater Dothideomycetes. Fungal Diversity 105 (1): 319-575. https://doi.org/10.1007/s13225-020-00463-5

- $\quad$ Goh TK, Hyde KD (1999) Fungi on submerged wood and bamboo in the Plover Cove Reservoir, Hong Kong. Fungal Diversity 3: 57-85.

- Henningsson M (1974) Aquatic lignicolous fungi in the Baltic and along the west coast of Sweden. Svensk Botanisk Tidskrift 68: 401-425.

- Hyde KD, Jones EBG, Liu J, Ariyawansa H, Boehm E, Boonmee S, Braun U, Chomnunti P, Crous P, Dai D, Diederich P, Dissanayake A, Doilom M, Doveri F, Hongsanan S, Jayawardena R, Lawrey J, Li Y, Liu Y, Lücking R, Monkai J, Muggia L, Nelsen M, Pang K, Phookamsak R, Senanayake I, Shearer C, Suetrong S, Tanaka K, Thambugala K, Wijayawardene N, Wikee S, Wu H, Zhang Y, Aguirre-Hudson B, Alias SA, Aptroot A, Bahkali A, Bezerra J, Bhat DJ, Camporesi E, Chukeatirote E, Gueidan C, Hawksworth D, Hirayama K, De Hoog S, Kang J, Knudsen K, Li W, Li X, Liu Z, Mapook A, McKenzie EC, Miller A, Mortimer P, Phillips AL, Raja H, Scheuer C, Schumm F, Taylor J, Tian Q, Tibpromma S, Wanasinghe D, Wang Y, Xu J, Yacharoen S, Yan J, Zhang M (2013) Families of Dothideomycetes. Fungal Diversity 63 (1): 1-313. https://doi.org/10.1007/s13225-013-0263-4

- Hyde KD, Hongsanan S, Jeewon R, Bhat DJ, McKenzie EC, Jones EBG, Phookamsak $\mathrm{R}$, Ariyawansa H, Boonmee S, Zhao Q, Abdel-Aziz FA, Abdel-Wahab M, Banmai S, Chomnunti P, Cui B, Daranagama D, Das K, Dayarathne M, de Silva N, Dissanayake A, Doilom M, Ekanayaka A, Gibertoni TB, Góes-Neto A, Huang S, Jayasiri S, Jayawardena R, Konta S, Lee HB, Li W, Lin C, Liu J, Lu Y, Luo Z, Manawasinghe I, Manimohan P, Mapook A, Niskanen T, Norphanphoun C, Papizadeh M, Perera R, Phukhamsakda C, Richter C, de A. Santiago ACM, Drechsler-Santos ER, Senanayake I, Tanaka K, Tennakoon TMDS, Thambugala K, Tian Q, Tibpromma S, Thongbai B, Vizzini A, Wanasinghe D, Wijayawardene $\mathrm{N}$, Wu H, Yang J, Zeng X, Zhang $\mathrm{H}$, Zhang J, Bulgakov T, Camporesi E, Bahkali A, Amoozegar M, Araujo-Neta LS, Ammirati J, Baghela A, Bhatt RP, Bojantchev D, Buyck B, da Silva GA, de Lima CLF, de Oliveira RJV, de Souza CAF, Dai Y, Dima B, Duong TT, Ercole E, Mafalda-Freire F, Ghosh A, Hashimoto A, Kamolhan S, Kang J, Karunarathna S, Kirk P, Kytövuori I, Lantieri A, Liimatainen K, Liu Z, Liu X, Lücking R, Medardi G, Mortimer P, Nguyen TTT, Promputtha I, Raj KNA, Reck M, Lumyong S, Shahzadeh-Fazeli SA, Stadler M, Soudi MR, Su H, Takahashi T, Tangthirasunun N, Uniyal P, Wang Y, Wen T, Xu J, Zhang Z, Zhao Y, Zhou J, Zhu L (2016) Fungal diversity notes 367-490: taxonomic and phylogenetic contributions to fungal taxa. Fungal Diversity 80 (1): 1-270. https://doi.org/10.1007/s13225-016-0373-x Hyde KD, Norphanphoun C, Abreu V, Bazzicalupo A, Thilini Chethana KW, Clericuzio M, Dayarathne M, Dissanayake A, Ekanayaka A, He M, Hongsanan S, Huang S, Jayasiri S, Jayawardena R, Karunarathna A, Konta S, Kušan I, Lee H, Li J, Lin C, Liu N, Lu Y, Luo Z, Manawasinghe I, Mapook A, Perera R, Phookamsak R, Phukhamsakda C, Siedlecki I, Soares AM, Tennakoon D, Tian Q, Tibpromma S, Wanasinghe D, Xiao Y, Yang J, Zeng X, Abdel-Aziz F, Li W, Senanayake I, Shang Q, Daranagama D, de Silva $\mathrm{N}$, Thambugala K, Abdel-Wahab M, Bahkali A, Berbee M, Boonmee S, Bhat DJ, 
Bulgakov T, Buyck B, Camporesi E, Castañeda-Ruiz R, Chomnunti P, Doilom M, Dovana F, Gibertoni T, Jadan M, Jeewon R, Jones EBG, Kang J, Karunarathna S, Lim YW, Liu J, Liu Z, Plautz HL, Lumyong S, Maharachchikumbura SN, Matočec N, McKenzie EC, Mešić A, Miller D, Pawłowska J, Pereira O, Promputtha I, Romero A, Ryvarden L, Su H, Suetrong S, Tkalčec Z, Vizzini A, Wen T, Wisitrassameewong K, Wrzosek M, Xu J, Zhao Q, Zhao R, Mortimer P (2017) Fungal diversity notes 603-708: taxonomic and phylogenetic notes on genera and species. Fungal Diversity 87 (1): 1-235. https://doi.org/10.1007/s13225-017-0391-3

Hyde KD, Tennakoon D, Jeewon R, Bhat DJ, Maharachchikumbura SN, Rossi W, Leonardi M, Lee HB, Mun HY, Houbraken J, Nguyen TT, Jeon SJ, Frisvad JC, Wanasinghe D, Lücking R, Aptroot A, Cáceres MS, Karunarathna S, Hongsanan S, Phookamsak R, de Silva N, Thambugala K, Jayawardena R, Senanayake I, Boonmee S, Chen J, Luo Z, Phukhamsakda C, Pereira O, Abreu V, Rosado AWC, Bart B, Randrianjohany E, Hofstetter V, Gibertoni T, Soares AMdS, Plautz HL, Sotão HMP, Xavier WKS, Bezerra JDP, de Oliveira TGL, de Souza-Motta CM, Magalhães OMC, Bundhun D, Harishchandra D, Manawasinghe I, Dong W, Zhang S, Bao D, Samarakoon M, Pem D, Karunarathna A, Lin C, Yang J, Perera R, Kumar V, Huang S, Dayarathne M, Ekanayaka A, Jayasiri S, Xiao Y, Konta S, Niskanen T, Liimatainen K, Dai Y, Ji X, Tian $X$, Mešić A, Singh S, Phutthacharoen K, Cai L, Sorvongxay T, Thiyagaraja V, Norphanphoun C, Chaiwan N, Lu Y, Jiang H, Zhang J, Abeywickrama P, Aluthmuhandiram JS, Brahmanage R, Zeng M, Chethana T, Wei D, Réblová M, Fournier J, Nekvindová J, do Nascimento Barbosa R, dos Santos JEF, de Oliveira NT, Li G, Ertz D, Shang Q, Phillips AL, Kuo C, Camporesi E, Bulgakov T, Lumyong S, Jones EBG, Chomnunti P, Gentekaki E, Bungartz F, Zeng X, Fryar S, Tkalčec Z, Liang J, Li G, Wen T, Singh PN, Gafforov Y, Promputtha I, Yasanthika E, Goonasekara I, Zhao R, Zhao Q, Kirk P, Liu J, Yan J, Mortimer P, Xu J, Doilom M (2019) Fungal diversity notes 1036-1150: taxonomic and phylogenetic contributions on genera and species of fungal taxa. Fungal Diversity 96 (1): 1-242. https://doi.org/10.1007/s13225-019-00429-2

- Hyde KD, de Silva NI, Jeewon RB, et al. (2020) AJOM new records and collections of fungi: 1-100. Asian Journal of Mycology 3 (1): 22-294. https://doi.org/10.5943/ajom/ $\underline{3 / 1 / 3}$

- Iturrieta-González I, Gené J, Guarro J, Castañeda-Ruiz R, García D (2018) Neodendryphiella, a novel genus of the Dictyosporiaceae (Pleosporales). MycoKeys 37: 19-38. https://doi.org/10.3897/mycokeys.37.27275

- Jayasiri S, Hyde K, Ariyawansa H, Bhat J, Buyck B, Cai L, Dai Y, Abd-Elsalam K, Ertz D, Hidayat I, Jeewon R, Jones EBG, Bahkali A, Karunarathna S, Liu J, Luangsa-ard JJ, Lumbsch HT, Maharachchikumbura SN, McKenzie EC, Moncalvo J, Ghobad-Nejhad M, Nilsson H, Pang K, Pereira O, Phillips AL, Raspé O, Rollins A, Romero A, Etayo J, Selçuk F, Stephenson S, Suetrong S, Taylor J, Tsui CM, Vizzini A, Abdel-Wahab M, Wen T, Boonmee S, Dai DQ, Daranagama D, Dissanayake A, Ekanayaka A, Fryar SC, Hongsanan S, Jayawardena R, Li W, Perera R, Phookamsak R, de Silva N, Thambugala K, Tian Q, Wijayawardene N, Zhao R, Zhao Q, Kang J, Promputtha I (2015) The faces of Fungi database: fungal names linked with morphology, phylogeny and human impacts. Fungal Diversity 74 (1): 3-18. https://doi.org/10.1007/s13225$\underline{015-0351-8}$ 
- $\quad$ Katoh K, Standley DM (2013) MAFFT Multiple sequence alignment software version 7: Improvements in performance and usability. Molecular Biology and Evolution 30 (4): 772-780. https://doi.org/10.1093/molbev/mst010

- $\quad$ Kirschner R, Pang K, Jones EBG (2013) Two cheirosporous hyphomycetes reassessed based on morphological and molecular examination. Mycological Progress 12 (1): 29-36. https://doi.org/10.1007/s11557-012-0812-3

- $\quad$ Liu NG, Hongsanan S, Yang J, et al. (2017) Dendryphiella fasciculata sp. nov. and notes on other Dendryphiella species. Mycosphere 8 (9): 1575-1586. https://doi.org/ 10.5943/mycosphere/8/9/12

- $\quad$ Li WL, Luo ZL, Liu JK, Bhat DJ, Bao DF, Su HY, Hyde KD (2017) Lignicolous freshwater fungi from China I: Aquadictyospora lignicola gen. et sp. nov. and new record of Pseudodictyosporium wauense from northwestern Yunnan Province. Mycosphere 8 (10): 1587-1597. https://doi.org/10.5943/mycosphere/8/10/1

- $\quad$ Luo ZL, Hyde KD, Liu JK, Bhat DJ, Bao DF, Li WL, Su HY (2018) Lignicolous freshwater fungi from China II: Novel Distoseptispora (Distoseptisporaceae) species from northwestern Yunnan Province and a suggested unified method for studying lignicolous freshwater fungi. Mycosphere 9 (3): 444-461. https://doi.org/10.5943/mycosphere/9/3/2

- Matsushima T (1983) Matsushima Mycological Memoirs No. 3. Mycologia 76 (2). https://doi.org/10.2307/3793127

- Nylander JAA, Uppsala University (2004) MrModeltest 2.0 Program distributed by the author. Evolutionary Biology Centre.

- Phookamsak R, Hyde KD, Jeewon R, Bhat DJ, Jones EBG, Maharachchikumbura SSN, Raspé O, Karunarathna SC, Wanasinghe DN, Hongsanan S, Doilom M, Tennakoon DS, Machado AR, Firmino AL, Ghosh A, Karunarathna A, Mešić A, Dutta AK, Thongbai B, Devadatha B, Norphanphoun C, Senwanna C, Wei D, Pem D, Ackah FK, Wang GN, Jiang HB, Madrid H, Lee HB, Goonasekara ID, Manawasinghe IS, Kušan I, Cano J, Gené J, Li J, Das K, Acharya K, Raj KNA, Latha KPD, Chethana KWT, He MQ, Dueñas M, Jadan M, Martín MP, Samarakoon MC, Dayarathne MC, Raza M, Park MS, Telleria MT, Chaiwan N, Matočec N, de Silva NI, Pereira OL, Singh PN, Manimohan P, Uniyal P, Shang QJ, Bhatt RP, Perera RH, Alvarenga RLM, Nogal-Prata S, Singh SK, Vadthanarat S, Oh SY, Huang SK, Rana S, Konta S, Paloi S, Jayasiri SC, Jeon SJ, Mehmood T, Gibertoni TB, Nguyen TTT, Singh U, Thiyagaraja V, Sarma VV, Dong W, Yu XD, Lu YZ, Lim YW, Chen Y, Tkalčec Z, Zhang ZF, Luo ZL, Daranagama DA, Thambugala KM, Tibpromma S, Camporesi E, Bulgakov TS, Dissanayake AJ, Senanayake IC, Dai DQ, Tang LZ, Khan S, Zhang H, Promputtha I, Cai L, Chomnunti P, Zhao RL, Lumyong S, Boonmee S, Wen TC, Mortimer PE, Xu J (2019) Fungal diversity notes 929-1035: taxonomic and phylogenetic contributions on genera and species of fungi. Fungal Diversity 95 (1): 1-273. https://doi.org/10.1007/s13225-019-00421-w

- Phukhamsakda C, McKenzie EHC, Phillips AJL, Gareth Jones EB, Jayarama Bhat D, Stadler M, Bhunjun CS, Wanasinghe DN, Thongbai B, Camporesi E, Ertz D, Jayawardena RS, Perera RH, Ekanayake AH, Tibpromma S, Doilom M, Xu J, Hyde KD (2020) Microfungi associated with Clematis (Ranunculaceae) with an integrated approach to delimiting species boundaries. Fungal Diversity 102 (1): 1-203.

https://doi.org/10.1007/s13225-020-00448-4

- Rajeshkumar KC, Verma RK, Boonmee S, Chandrasiri S, Hyde KD, Ashtekar N, Lad S, Wijayawardene NN (2021) Paradictyocheirospora tectonae, a novel genus in the family 
Dictyosporiaceae from India. Phytotaxa 509 (3). https://doi.org/10.11646/phytotaxa. 509.3.1

- $\quad$ Rambaut A, Drummond A (2008) Fig tree: tree figure drawing tool, version 1.2.2. Institute of Evolutionary Biology, University of Edinburgh.

- Rannala B, Yang Z (1996) Probability distribution of molecular evolutionary trees: A new method of phylogenetic inference. Journal of Molecular Evolution 43 (3): 304-311. https://doi.org/10.1007/bf02338839

- $\quad$ Ronquist F, Huelsenbeck JP (2003) MrBayes 3: Bayesian phylogenetic inference under mixed models. Bioinformatics 19 (12): 1572-1574. https://doi.org/10.1093/

bioinformatics/btg180

- Senanayake IC, Rathnayaka AR, Marasinghe DS, et al. (2020) Morphological approaches in studying fungi: collection, examination, isolation, sporulation and preservation. Mycosphere 11 (1): 2678-2754. https://doi.org/10.5943/mycosphere/ $11 / 1 / 20$

- Silvestro D, Michalak I (2011) raxmIGUI: a graphical front-end for RAxML. Organisms Diversity \& Evolution 12 (4): 335-337. https://doi.org/10.1007/s13127-011-0056-0

- Stamatakis A, Alachiotis N (2010) Time and memory efficient likelihood- based tree searches on phylogenomic alignments with missing data. Bioinformatics 26 (12): 132-139. https://doi.org/10.1093/bioinformatics/btq205

- Tanaka K, Hirayama K, Yonezawa H, Hatakeyama S, Harada Y, Sano T, Shirouzu T, Hosoya T (2009) Molecular taxonomy of bambusicolous fungi: Tetraplosphaeriaceae, a new pleosporalean family with Tetraploa-like anamorphs. Studies in Mycology 64:

175-209. https://doi.org/10.3114/sim.2009.64.10

- Tibell S, Tibell L, Pang KL, Calabon M, Jones EBG (2020) Marine fungi of the Baltic Sea. Mycology 11 (3): 195-213. https://doi.org/10.1080/21501203.2020.1729886

- Tibpromma S, Hyde KD, McKenzie EHC, Bhat DJ, Phillips AJL, Wanasinghe DN, Samarakoon MC, Jayawardena RS, Dissanayake AJ, Tennakoon DS, Doilom M, Phookamsak R, Tang AMC, Xu Jc, Mortimer PE, Promputtha I, Maharachchikumbura SSN, Khan S, Karunarathna SC (2018) Fungal diversity notes 840-928: micro-fungi associated with Pandanaceae. Fungal Diversity 93 (1): 1-160. https://doi.org/10.1007/ s13225-018-0408-6

- Wang RX, Luo ZL, Hyde KD, Bhat DJ, Su XJ, Su HY (2016) New species and records of Dictyocheirospora from submerged wood in north-western Yunnan, China.

Mycosphere 7 (9): 1357-1367. https://doi.org/10.5943/mycosphere/7/9/9

- Yang J, Liu JK, Hyde KD, Jones EBG, Liu ZY (2018) New species in Dictyosporium, new combinations in Dictyocheirospora and an updated backbone tree for Dictyosporiaceae. MycoKeys 36: 83-105. https://doi.org/10.3897/mycokeys. 36.27051. figure4

- $\quad$ Zhang Y, Schoch CL, Fournier J, Crous PW, de Gruyter J, Woudenberg JHC, Hirayama K, Tanaka K, Pointing SB, Spatafora JW, Hyde KD (2009) Multi-locus phylogeny of Pleosporales: a taxonomic, ecological and evolutionary re-evaluation. Studies in Mycology 64: 85-102. https://doi.org/10.3114/sim.2009.64.04

- Zhang Y, Crous PW, Schoch CL, Hyde KD (2012) Pleosporales. Fungal Diversity 53: 1-221. https://doi.org/10.1007/s13225-011-0117-x 